\title{
EVALUATION OF PHYSICAL MECHANICAL PROPERTIES OF EXPERIMENTAL GRANULATED CATTLE MANURE COMPOST FERTILIZER
}

\author{
Ramunas Mieldazys $^{1}$, Egle Jotautiene ${ }^{1}$, Algirdas Jasinskas ${ }^{1}$, Aivars Aboltins ${ }^{2}$ \\ ${ }^{1}$ Aleksandras Stulginskis University, Lithuania; ${ }^{2}$ Latvia University of Agriculture \\ ramunas.mieldazys@asu.lt, egle.jaotautiene@asu.lt, algirdas.jasinskas@asu.lt, \\ aivars.aboltins@inbox.lv
}

\begin{abstract}
Currently, there are searches for new and more rational ways to use biological waste for new forms of energy, creating fertilizers, building materials and other products. One kind of this biodegradable waste management is pelleting as the processing of recyclable materials into organic products. In the EU today only $5 \%$ of bio-waste is recycled. According to estimates, if more bio-waste was recycled, it could replace up to $30 \%$ of non-organic fertilizers. Currently, the EU imports around 6 million tons of phosphates a year but could replace up to $30 \%$ of this total by extraction from sewage sludge, biodegradable waste, meat and bone meal or manure. According to the EU legal requirements manure is considered to be waste that the livestock owner has to account for and eliminate using as crop fertilizer and not polluting the environment. Manure compost pelleting can increase the bulk density, improve storability, reduce transportation costs, and make these materials easier to handle using the existing handling and storage equipment. Granulation process parameters and factors affecting the manure-based compost of organic granular fertilizer physical-mechanical properties were investigated. Manure raw material samples were dried naturally till $42 \%$ humidity. Before pelletizing the samples were dried artificially till $28 \%$ humidity. There were prepared 5 experimental manure samples in laboratory conditions and pelletized mixtures of manure waste with molasses and lime sludge add. For pellet production a small capacity $7.5 \mathrm{~kW}$ granulator was used, with a horizontal granulator matrix, the diameter of the pellets was $6 \mathrm{~mm}$. During the researches there were estimated various physical - mechanical characteristics: biometric indicators (dimensions, mass), raw material and pellet volume and density, material and pellet humidity, pellet strength.
\end{abstract}

Keywords: organic waste, manure, pelletizing, fertilizer, pellet strength.

\section{Introduction}

Organic fertilizer application through composting of local materials is the easy way, which enhances the quality of life for farmers and society, and in the long term it enhances the environmental quality and the resource in which agriculture depends. However, there are limits of compost application, so pelletized compost was developed for an alternative fertilization including for soil and nutrient conservation [1]. Production of fertilizers from renewable organic waste sources (such as sewage sludge, manure, animal wastes, wood wastes, etc.) using biological and chemical processes represents an important area of bio-fertilizer production. Not only in the European countries, but all over the world scientists make every effort to recycle organic waste products and obtain bio-fertilizers for soil fertility improvement. Farmyard manure is also a valuable organic waste that has been traditionally used as a soil conditioner in agricultural fields. The organic component of solid waste contains sufficient amounts of nutrients that can be used as biological fertilizers. While, on the other hand, organic wastes have the potential to be used not only as a source of nutrient supply but also as soil conditioners to improve the characteristics of the soil [2].

Pelletizing is a method of increasing the bulk density of biomass by mechanical pressure. Pellets have a low moisture content wet basis for safe storage, and a high bulk density for efficient transport and storage. Some of other benefits of compost pellets are: reducing the conservation space because of densification, suitable for mechanization, suitable for residential places because of producing no dust, no pollution for environment, more precision with spreaders and reducing manure consumption, suitable for transporting to long distances, suitable for planters and no need to separate operation, ability of long time conservation, ability of adding other materials for increasing the quality of pellets [3].

According to scientific researches the crush strength is the most commonly used method for measuring the overall hardness of fertilizer granules. It is defined as the minimum force required to crush individual particles. For fertilizers it is a useful factor in predicting the expected handling and storage properties of the sample. For this reason the crushing strength of the samples was compared both by a simple finger test, which is useful for quick field measurements, and by a hardness tester instrument [4]. 
The best properties of the compound fertilizers (marketable fraction part - from $63.0 \%$ to $85.0 \%$ and the static strength of granules - from $34.60 \mathrm{~N}$ per granule to $43.18 \mathrm{~N}$ per granule) were obtained when the content of irrigation water in the raw material mixture was 7-9\% (15-20 ml per $200 \mathrm{~g}$ of the mixture) and the recycle was 10-20\%. It was found that the properties of the fertilizer depend on the irrigation water content and the particle size of the raw material. The origin of the raw materials had a negligible influence [5].

When assessing the suitability of manure compost for granulation, it has been established that this organic waste dried up to $10-12 \%$ content humidity may be granulated using traditional feed granulators. The very process of granulation does not require any special equipment [6].

According to Lithuanian researchers it was found that the experimental manure compost pellets (named GM-6) with static stability limit $430 \mathrm{~N}$ were the most mechanically stable when subject to vertical compression, and the deformation level up to 1.2-1.3 $\mathrm{mm}$ [7].

This paper is based on an investigation that aimed at determining the manure compost physical properties for safe and more productive reuse of organic wastes (cattle manure, molasses, lime sludge) in agriculture through granulation.

\section{Materials and methods}

The following physical-mechanical characteristics of granulated cattle compost manure fertilizers were investigated and determined: the moisture of granules; biometric parameters of granules: measurements, mass, density; filled density of granules; strength of granules. This research has been performed using the standard and modified methods.

Raw material preparation. The manure compost samples were dried naturally till $42 \%$ humidity. The samples were dried till about $28 \%$ humidity for 48 hours in the ventilation canal with slow heated air flow. After separation the material was placed to the hammer mill, where it was grinded in fine powder (particle dimensions $0.1-1.0 \mathrm{~mm}$ ) like form. The mill was mixed thoroughly to achieve homogeneity.

Pellet production. There were produced 5 variants of cattle manure pellets in laboratory conditions. The samples were wetted by sprinkling water on them. The first sample was wetted with water without any supplement named GA1. Other samples were wetted by sprinkling water with molasses and lime sludge additional materials (supplements). Mixing ratio among the raw material with water and molasses emulsion rate $1: 1$ named GA2 and rate 1:2 named GA3. The raw material with water and lime sludge rate 1:1 named GA 4 and rate 1:2 named GA5. For pellet production a small capacity granulator $7.5 \mathrm{~kW}$ was used with a horizontal granulator matrix with $6 \mathrm{~mm}$ diameter holes. The main constructive parameters of the granulator: the distance between the flat die and rollers is $0.05-0.30 \mathrm{~mm}$; the rotation speed of the die is $3,000 \mathrm{~min}^{-1}$. When the pellets cooled, their biometric parameters (dimensions, humidity, volume and density) were evaluated. The pellet parameters were determined by measuring their height and diameter (accuracy to $0.05 \mathrm{~mm}$ ). Experimental trials were randomly selected with 10 pellets. The pellet weight was assessed by KERN ABJ scales (accuracy to $0.001 \mathrm{~g}$ ). The weights were calculated for each type of plant using 10 of the granules to obtain the average error. The pellet volume was calculated using the pellet size (diameter and length). Average mass meanings of the measured 5 sort granules were calculated, and they were written down with the error.

Mill density. Empty $6 \mathrm{dm}^{3}$ cylinder is weighted. The prepared mill is filled in the cylinder till the upper edge. The vessel with mill is weighted and the mass of mill is calculated.

Mill and pellet moisture content. The mill moisture content is determined according to the standard methodology. The samples were weighted and dried for 24 hours in the temperature of 105 ${ }^{\circ} \mathrm{C}$. The pellet moisture content was determined analogous to the mill in a laboratory drying chamber oven according to the standard method. The pellet volume was calculated using the pellet size (diameter and length). The moisture content of each sample was calculated in percents. The pellet and mill moisture content was determined in a laboratory drying chamber oven. The dry matter content in percents was estimated drying $50 \mathrm{~g}$ evenly overspread $20 \mathrm{~mm}$ thickness raw material sample in the temperature of $105^{\circ} \mathrm{C}$ till the mass is unchanging. Calculations were made according to the standard EN 13040. 
Density of granules. Unit density of the pellets was determined by calculating the weight and volume of a few pellets individually. The volume of each pellet was determined. Knowing the determined measurements of the granules (diameters), their volume is calculated $V_{g r}$ :

$$
V_{g r}=\frac{\pi \cdot d^{2}}{4} l,
$$

where $d$-diameter of granule, $\mathrm{mm}$;

$l$ - length of granule, $\mathrm{mm}$.

While knowing the mass of a granule (exactness of weight indices is $0.01 \mathrm{~g}$ ), the density of the granule mass $\rho_{g r}$ is calculated:

$$
\rho_{g r}=\frac{m_{g r}}{V_{g r}},
$$

where $\rho_{g r}$ granule mass density, $\mathrm{kg} \cdot \mathrm{m}^{-3}$.

Knowing the moisture of the granules, the density of dry material (DM) of each sort of organic fertilizers and the data spread reliable interval (error) are calculated.

Bulk density of pellets. Bulk density of pellets was determined according to the LST EN 15103:2010. The pellets were transferred into a cylindrical container up to the top level. The extra material was removed and weight. The bulk density of the pellets was calculated by deducting the weight of the empty container from the collective weight of the pellets and the container. The bulk density was calculated by dividing the mass by the container volume.

Pellet strength measuring. Pellet strength tests were made in the research machine "Instron 5960" and the command and parameter registration computer system "Bluehill". Optional static load operation of the pellet rate $\left(20 \mathrm{~mm} \cdot \mathrm{min}^{-1}\right)$, sets the movement limits and automatic shutdown. The tests were performed by placing the granules on a plane with horizontal and vertical loads. Tests were made for 5 times for each sample. Compressive tests selected granules of the height to diameter ratio greater than 2:1 (height $-12 \mathrm{~mm}$; diameter $-6 \mathrm{~mm}$ ). The test results were registered every 0.1 second until the pellet completely crushed. The measuring error was $0.02 \%$. Having performed the experimental research, the received research data were processed by statistic mathematical methods. During data processing, average values and their confidence intervals (CI) under the 0.95 probability level were found and figures were made using MS Office program Excel 2010.

Fall and natural slope angles. Pellet fall and natural slope angles were determined applying the method of pellets sliding down freely from a container, and measured with the accuracy of \pm 1.0 degree. The measurements were repeated 3 times. A portion of chaff ( $5 \mathrm{~kg}$ mass) was poured into a rectangular container. After opening the valve, part of the chaff mass crumbled off. With the help of a turned ruler and protractor the angles of crumble were measured, the angle of natural slope (on the horizontal plane) and the angle of fall (at the bottom of the container) [8]. Each test was replicated three times and the mean values of the angles and their error values were calculated.

\section{Results and discussion}

Granulometric composition of granulated compost fertilizers depends on the pellet diameter. It has been determined that the produced granulated fertilizers were in the range of the pellet diameter from $5.74 \pm 0.9 \mathrm{~mm}$. Average pellet weight was about $1.09 \pm 0.9 \mathrm{~g}$. The pellet average length $13.2 \pm 5.6 \mathrm{~mm}$. Pelletizing the raw material with such kind of traditional granulator, with a horizontal granulator matrix, we got big pellet length scattering. For fertilizer production it is better to use granulators with adjustable pellet length.

The analysed and determined biometrical parameters of granulated organic fertilizer granules the moisture and density, are presented in Table 1. As it is seen from the presented in the table characteristics manure compost granules have high density $\left(789 \pm 40.4 \mathrm{~kg}^{-3}\right)$. 
The density of pellets depends on the raw organic waste and moisture content. Conveyance, handling efficiency and storage space provisions depend on the density of pellets. Sufficient storage is needed in order to safely handle a huge supply of pellet stock. Low storage space for high bulk density of pellets is required with greater efficiency.

Table 1

\section{Physical parameters of composted manure raw material and tested manure compost pellets}

\begin{tabular}{|c|c|c|}
\hline Indicator & Result & Methods \\
\hline $\begin{array}{c}\text { Manure raw material bulk } \\
\text { density, } \mathrm{kg} \cdot \mathrm{m}^{-3}\end{array}$ & $556.4 \pm 5.81$ & LST EN 15104 \\
\hline Mill moisture content $\%$ & $23.5 \pm 0.32$ & LST EN 14774 \\
\hline Dry matter content, $\%$ & 76.5 & LST EN 13040 \\
\hline Pellet average density, $\mathrm{kg} \cdot \mathrm{m}^{-3}$ & $789 \pm 40.4$ & LST EN 1237 \\
\hline Pellet bulk density, $\mathrm{kg} \cdot \mathrm{m}^{-3}$ & $584 \pm 16.8$ & LST EN 1237 \\
\hline
\end{tabular}

Humidity plays a role of plasticizer and enhances particle interactions. Optimal moisture is usually determined by the experimental method and is different for other constructions of granulators (piston, screw or matrix type). Sufficient pellet density is possible to achieve in lower moisture raw material, but the compressive strength of pellets can be significantly lower. With increasing raw material humidity reduces the pelletizing capacity, there are changes in the form of granules, the strength of pellets is increasing as well.

Naturally dried raw material humidity was $42 \%$. In our previous experiments it was estimated that optimal humidity for manure compost pelletizing is $14 \%$ till $28 \%$ samples were dried till about $28 \%$ humidity for 48 hours in the ventilation canal with slow heated air flow to achieve such humidity. After milling the raw material mill moisture is $23.5 \%$. After pelletizing average pellet density is $789 \mathrm{~kg} \cdot \mathrm{m}^{-3}$. In the technological operations assessment shown in Fig. 1 artificially dried material density decreased till $395 \mathrm{~kg} \cdot \mathrm{m}^{-3}$ because removed humidity and milled material density increased till $556 \mathrm{~kg} \cdot \mathrm{m}^{-3}$.

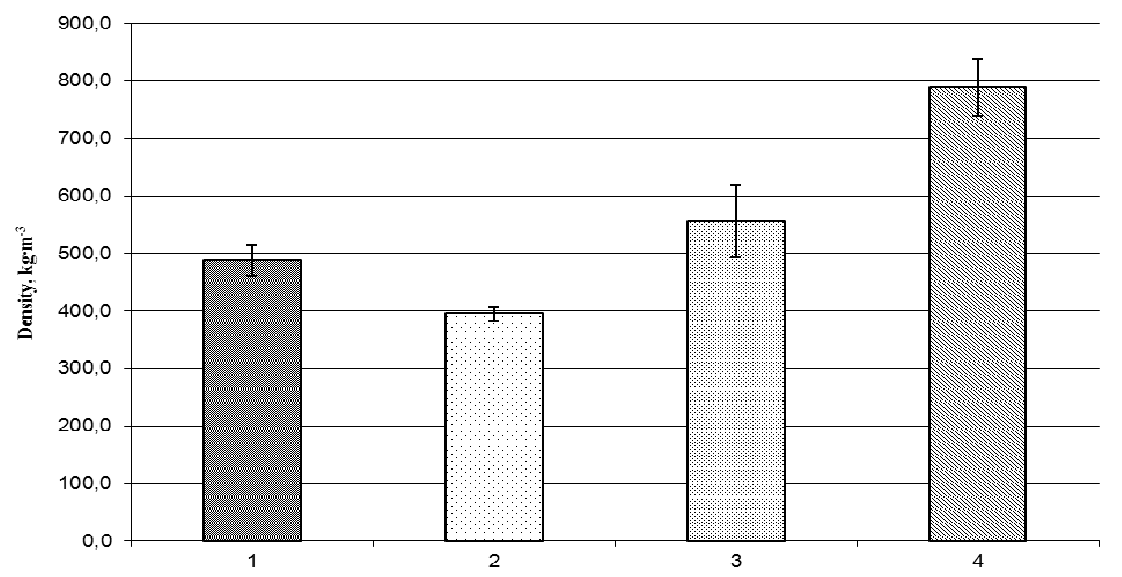

Fig. 1. Raw material and pellet density comparison: 1 - naturally dried material density, $\mathrm{kg} \cdot \mathrm{m}^{-3}$;

2 - artificially dried material density, $\mathrm{kg} \cdot \mathrm{m}^{-3} ; 3$ - milled material density, $\mathrm{kg} \cdot \mathrm{m}^{-3}$; 4 - pellet density, $\mathrm{kg} \cdot \mathrm{m}^{-3}$

Compression strength (or crushing resistance or hardness) is the maximum crushing load a pellet can withstand before cracking or breaking. A good organic fertilizer should be firm enough to pass through a disc spreader without grinding to powder, also for transportation and storage of granules.

Having performed a research in the compression strength of five sorts of granules of organic fertilizers, we received the results that are presented in Fig. 2. During the tests, the beginning of deformation of the force under which a granule is disintegrated was determined in horizontal and vertical directions. 
Pellets GA1 without any supplements were used like a control sample in comparison with other samples. Analysing the pellets GA1 it may be seen that pellets under the force of $425 \mathrm{~N}$ in horizontal compression and $228 \mathrm{~N}$ in vertical compression disintegrated totally. With increasing the concentration of molasses we observe stronger binding properties of the material. The strength of the pellets with molasses add GA3 (rate 1:2) reached $491 \mathrm{~N}$ in horizontal direction and $451 \mathrm{~N}$ in vertical direction. Increasing the concentration of lime sludge pellets the compressive strength decreases increasing the fragility of the pellets. The strength of the pellets with lime sludge add GA5 (rate 1:2) decreased till $378 \mathrm{~N}$ in horizontal direction and $282 \mathrm{~N}$ in vertical direction. The molasses add cattle manure compost pellets strength increased from $6 \%$ to $9 \%$ and the lime sludge add to $6 \%$. The results of the experiments on the tested pellets compressed vertically and horizontally show that their strengths differ from $4 \%$ to $47 \%$.

Compared with organic and mineral pellets tested by other scientists our tested experimental pellets show higher strength. It can be said that the organic fertilizer pellets are sufficiently strong, much stronger than the mineral, which, like calcium ammonium nitrate, granular strength varies within $35-70 \mathrm{~N}$.

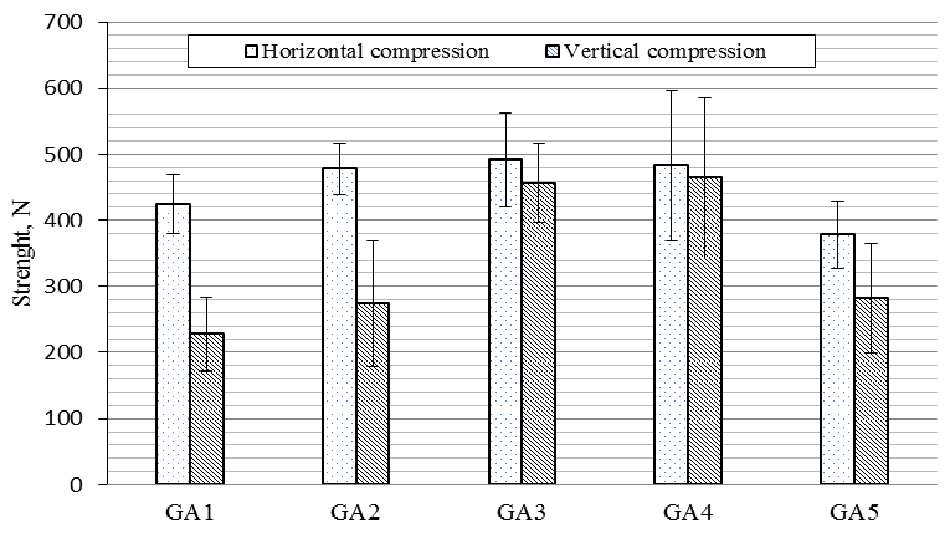

Fig. 2. Cattle manure compost pellets strength test: GA1 - pure, GA2 - with molasses add (water and molasses emulsion rate 1:1); GA3 - with molasses add (1:2), GA4 - with lime sludge add (1:1); GA5 - with lime sludge add (1:2)

The results of the measurements of the cattle manure compost fertilizer pellets fall angle and natural slope angle as indicators characterizing pourability of bulk materials are presented in Figure 3.

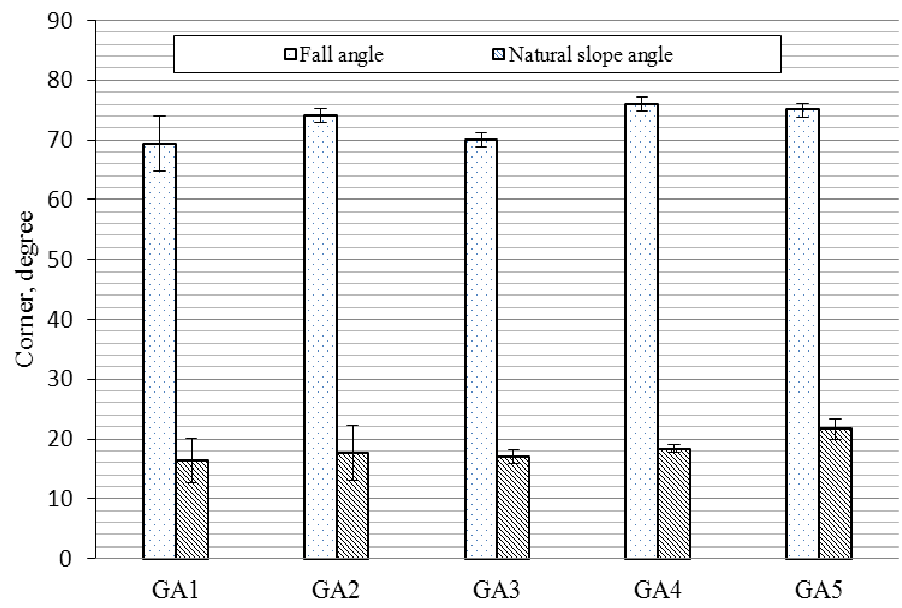

Fig. 3. Fall angle and natural slope angle of pellets: GA1 - pure, GA 2 - with molasses add (water and molasses emulsion rate 1:1) ; GA3 - with molasses add (1:2), GA4 - with lime sludge add (1:1); GA5 - with lime sludge add (1:2) 
The determined natural slope angles vary from 16.3 till 21.7 degrees. The fall angle meanings are not close to the natural slope angles, they vary from 69.3 till 76.0 degrees.

Mechanical properties of the pelletized product indicate the pellet resistance to the effects of external mechanical factors. All these granules are sufficiently resistant to operating load, and they may be transported and spread mechanically comfortably.

\section{Conclusions}

1. Pellets produced from raw material (optimal humidity $28 \%$ ) were in the range of the diameter from $5.74 \pm 0.9 \mathrm{~mm}$ and average length $13.2 \pm 5.6 \mathrm{~mm}$.

2. Density changes in technological operations of manure compost preparation and granulation varied from $395 \mathrm{~kg} \cdot \mathrm{m}^{-3}$ till $789 \mathrm{~kg} \cdot \mathrm{m}^{-3}$. Manure compost should be dried to $28 \%$ humidity while preparing raw material for granulation.

3. With increasing the concentration of molasses it is possible to achieve high strength of organic pellets $(491 \mathrm{~N})$.

4. It is unreasonable to increase the concentration of lime sludge more than the rate $1: 1$, because increasing of this concentration makes the pellet strength weaker.

5. Molasses and lime sludge add in cattle manure compost reduces the pellet strength from $4 \%$ till $9 \%$ in vertical and horizontal directions.

6. The determined fall angle meanings are not close to the natural slope angles, that is why it is better for organic fertilizer production to use granulators with adjustable pellet length.

\section{References}

1. Ngo B., Siriwattananon L. Suitable timing of application of pelletized compost and farmers acceptance in Cambodia. Journal ISSAAS Vol. 15 2009, No. 1: pp. 91-100.

2. Ali M., Khan Z.M., Raja I.A. Treatment of organic solid waste for reuse: a step towards zero waste, Science Vision Vol. 19 (1,2) 2013, pp. 63-6

3. Zafari A Kianmehr M.H., Factors affecting mechanical properties of biomass pellet from compost. Environmental Technology Vol. 35, 2014, pp. 478-486.

4. Latifian M., Liu J., Mattiasson B. Struvite-based fertilizer and its physical and chemical properties. Environmental Technology Vol. 33, 2012. pp. 2691-2697.

5. Šlinkšienė R., Zagorskis T. Compound fertilizers granulation using different materials and different ways, Chemical technology Vol. 65, No 1, 2014. pp. 54-62. (In Lithuanian)

6. Pocius A., Jotautienė E., Domeika R., Jasinskas A., Kučinskas V., Palšauskas M. Investigation of granulation process influence to granulated organic compost fertilizer properties. Engineering for rural development: 14th international scientific conference : proceedings, May 20-22, 2015. Vol. 14. pp. 829-834.

7. Pocius A., Jotautienė E., Pekarskas J., Palšauskas M. Investigation of physical-mechanical properties of experimental organic granular fertilizers. Engineering for rural development: 15th international scientific conference: proceedings, May 25-27, 2016. Vol. 15. p. 1115-1120.

8. Jasinskas A., Pekarskas J., Kučinskas V., Aboltins A. Investigation of natural magnesium mineral fertilizer granulation And determination of granule qualitative indicators. Engineering for rural development: 15th international scientific conference: proceedings, May 25-27, 2016. Jelgava, 2016. Vol. 15, pp. 647-652. 